\title{
Small cell carcinoma of the oesophagus: a rare and aggressive tumour
}

\author{
CTR Kasturi ${ }^{1}$, MB Smarawickrama ${ }^{2}$, BL Perera ${ }^{3}$, PK Ravindran ${ }^{4}$, AHMPAnuruddha $^{1}$ \\ ${ }^{1}$ Registrar in Surgery, ${ }^{3}$ Consultant Surgeon, ${ }^{4}$ Senior Registrar in Surgery, General Surgery Unit III, \\ Teaching Hospital, Karapitiya, Galle. \\ ${ }^{2}$ Lecturer in Anatomy, Faculty of Medicine, University of Ruhuna, Galle.
}

\section{Introduction}

Small cell carcinoma is a neuroendocrine tumour commonly encountered in lungs which comprises $25 \%$ of all bronchogenic carcinomata [1]. But it is uncommon to occur in the oesophagus.

\section{Case report}

A 63 year-old male presented with dysphagia for solids for 1 month. He also had epigastric discomfort, distention, regurgitation and loss of appetite. He had no malena or haematemesis. He was free of comorbid factors. There were no abnormalities found on examination except that he was thinly built. Upper gastrointestinal endoscopy showed a mass lesion at the lower end of the esophagus. Histology of the lesion revealed a poorly differentiated small cell carcinoma (SCC). Ultrasound scan of the abdomen \& computerised tomography of the chest showed no metastatic deposits. Lungs were free of tumour. Transhiatal esophagectomy was performed. The histology of the tumour was compatible with SCC of gastroesophageal junction. The stage was $\mathrm{T}_{2} \mathrm{~N}_{1} \mathrm{M}_{0}$. Two out of 8 lymph nodes were positive for tumour. Patient was referred to the oncologist for further management.

\section{Discussion}

Small cell carcinoma of the esophagus is a rare aggressive tumour with poor prognosis. It accounts for $0.05-4 \%$ of all esophageal malignancies [2]. In a study conducted in China (1989-2005), out of 4050 esophageal malignancies only 21 cases were SCC [2].
It occurs most frequently at lower esophagus but can also occur at upper or middle $3^{\text {rd }}$ as well [3]. It is more common in males with male to female ratio of 3.2:1 [2]. Its clinical course is similar to that of SCC of the lungs [4] and other extrapulmonary organs including the breast, ovary, uterine cervix, liver, salivary gland, stomach, colon, prostate, urinary bladder \& kidney [2]. It has a very rapid growth with doubling time of 20 days [3]. Systemic and lymphatic metastasis occur very early [3].

Dysphagia is the commonest presenting complaint [2]. This patient had a mixture of symptoms in addition to dysphagia. That may be due to the fact that he had the lesion at gastroesophageal junction. The duration of symptoms ranges from 1-3 months [2].

Histological diagnosis is not difficult. Microscopic picture is similar to small cell lung cancer consisting of round to spindle shaped cells with scanty cytoplasm, granular nuclei and inconspicuous nucleoli. Immunohistochemical labelling with Synaptophysin, Chromogranin A, CD 56, Neuron Specific Enolase and Thyroid Transcriptional Factor-1 can confirm the diagnosis [2]. In this patient, microscopy showed sheets of small round cells with hyperchromatic nuclei \& scanty cytoplasm. There were numerous mitoses, rosette formation and a trabecular arrangement. We could not confirm it by immunohistochemistry due to unavailability of resources.

Treatment of oesophageal small cell carcinoma in various studies showed a multimodality approach with surgical resection, chemotherapy and radiotherapy [2]. This patient is also being followed up by oncologists following surgery. 


\section{Case Reports}

Previous studies in different hospitals showed a median survival of 7.5 months (range $1-21$ months) [2]. But the recent Chinese study showed 18 months ranging from $3-71$ months [2]. This patient is now in his $4^{\text {th }}$ month after the diagnosis.

\section{Conclusions}

Small cell carcinoma is an aggressive tumour. It can occur in esophagus rarely. The diagnosis may not be difficult but need immunohistochemical methods to confirm. Treatment includes surgical resection with chemo and radiotherapy. However, it has a very poor prognosis.

\section{References}

1. Sir Alfred Cuschieri, Robert J. C. Steele, Abdool Rahim Moossa. Tumours of the lung. Essential Surgical Practice Higher Surgical Training in General Surgery $2002 ; \mathbf{4} ; 1163$.

2. Jin Ping Yun, Mei Fang Zhang, Jin Hui Hou Et al. Primary small cell carcinoma of the esophagus clinicopathological \& immunohistochemical features of 21 cases. BMC Cancer 2007; 7; 38 (Biomed abstract).

3. Robert L. Souhamy, Ian Tannock, Peter Hohenberger, Jean Claude Horiot. Small cell carcinoma esophagus. Oxford Textbook of Oncology 2002; $2 ; 1488$.

4. Sir Peter J. Morris, William C. Wood. Small cell carcinoma esophagus. Oxford Textbook of Surgery $2000 ; 2 ; 1292-3$. 